\title{
Physical, Unconscious, and Non-physical Factors of Attraction
}

\author{
Ciara Nadelkov ${ }^{\mathrm{a}}$
}

\begin{abstract}
Attraction is defined in many ways, and there is general idea that men and women have particular preferences in mates regarding physical attractiveness. Studies have found that physically, men prefer women with both a small waist and hips, and women prefer men with taller and more brawny bodies than themselves. However, there are unconscious factors, such as assessing a human leukocyte antigen complex through sense of smell, which many are not aware of. The most influential factor on attractiveness ratings is personality; while many are aware of their preference for a particular personality, it is less apparent than physical attractiveness preferences. Various assessments, physical, unconscious, and non-physical, form the foundation for ratings of interpersonal attraction.
\end{abstract}

Keywords: Attraction; Physical; Non-physical; Unconscious; Preference

\section{Physical and Non-physical Factors of Attraction}

Merriam Webster defines attraction as "the action or power of evoking interest, pleasure, or liking for someone or something." With the ability to make snap judgments about others within the first tenth of a second (Willis \& Todorov, 2007), people quickly know whom they find attractive and whom they find unattractive. The definition of what is attractive varies from person to person; generally, men are alleged to solely value physical appearance, while women are perceived to consider all factors of a potential mate. However, studies have indicated that both men and women value physical factors (Buss, 2003; Caryl et al., 2009) as well as non-physical factors (Hareli \& Weiner, 2000; Kniffin \& Wilson, 2004; Singh, Ng, Ong, \& Lin, 2008) in interpersonal attraction. Thus, interpersonal attraction is the assessment people make of others and has physical, unconscious, and non-physical facets.

\section{Physical Factors of Attraction}

Furham, Moutafi, and Baguma (2002) stated that women assume men's sole basis for attractiveness ratings is physical appearance. Yet, when contemplating potential mates, both men and women consider physical appearance. Male preference comprises of females with a small waist, small hips, and light weight (Furnham, Moutafi, \& Baguma, 2002). Buss (2003) surveyed over ten thousand people and discovered that the standards for female beauty are comparatively analogous throughout the world; men favor women with clear skin, full lips, long hair, symmetrical facial features, and a small waist-to-hip ratio of 0.7 (Buss, 2003). These results depict a fondness for smaller female body sizes, while Caryl et al. (2009) found that women select men with taller, more brawny bodies than themselves.

Physical attraction is not restricted to body shape and size; facial features are also assessed. Sammaknejad (2013) demonstrated that males use the proportion of the iris width to eye width as an indicator of youth and reproductive fitness. In turn, males give higher ratings of attractiveness to females with a larger proportion of iris width to eye width (Sammaknejad, 2013). Men also consider the scleral color, the white of the eye, when rating women's attractiveness.
This color varies from a bluish tone to a yellowish tone as one ages, and men prefer women with a bluish scleral color and rate them as more attractive (Sammaknejad, 2013). Grundl, Knoll, Eisenmann-Klein, and Prantl (2012) examined whether blue iridal color is correlated to an increase in attractiveness ratings of a person's eye area. Photographs of sixty women between the ages of 15 and 65 were presented to eighty participants. Participants rated the attractiveness of the person in the photograph on a 7-point Likert scale and were asked to estimate the age of the person. Analyses indicated no correlation between iridal color and attractiveness ratings, yet Grundl et al. (2012) concluded that the "blue-eyes stereotype" exists based on the participants' mentioning the color blue more often as a positive aspect than other iridal colors. It was also found that positive attractiveness ratings were associated with stimuli photographs with bright scleral color and large pupils, both indicative of youthfulness (Grundl et al., 2012).

Color also has a significant influence on men's attraction to women; the color red has historically influenced males's behavior toward women in non-human species, including baboons and chimpanzees (Kayser, Elliot, \& Feltman, 2010). In non-human species, females exhibit red on their body when close to ovulation, and a male's attraction increases, as demonstrated by an increase in mounting and masturbation (Bielert, Girolami, \& Jowell, 1989; Waitt, Gerald, Little, \& Krasielburd, 2006).

The attraction to red is exhibited in humans as well; Kayser, Elliot, and Feltman (2010) recently demonstrated this effect in undergraduate students. Kayser et al. (2010) asked twenty-two male United States undergraduate students to view a picture of a moderately attractive woman. This woman had previously received a mean attractiveness rating of 6.80 $(\mathrm{SD}=1.32$ ) on a 1 (not at all attractive) to 9 (extremely attractive) scale from a pilot test. The woman was wearing either a red or blue shirt, which was altered via photoshop, and the men were asked to look at the picture for five seconds and then answer two questions regarding their current feelings. Participants were then escorted to a room with a table and two chairs, expecting to meet and have a conversation with the woman. Each participant was seated, and waited a few moments before the experimenter stated that 
the woman could not make it. At the end of the experiment, the distance between the two chairs was measured and was found to negatively correlate to the participants' interest in the woman in the photo, as seen in Figure 1. By using stringent color controls, Kayser, Elliot, and Feltman (2010) concluded that the men were particularly attracted to the woman when she was wearing red, and this effect can be contributed to the hue of the color not the lightness or chroma.

When first meeting someone, one instinctively extends his or her hand to shake hands. Differing on a number of dimensions, including "limp versus firm, dry versus clammy, or warm versus cold" (Chaplin et al., 2000), handshakes are often assumed to be indicative of one's character, vary based on gender, and contribute to first impressions. Chaplin et al.'s (2000) study was designed to assess the existence of any gender differences in handshake characteristics and the relation between personality and handshakes. Chaplin et al. (2000) recruited one hundred and twelve college undergraduates to participate in the study, and trained advanced psychology students as handshake coders over the course of a month. The participants completed on personality questionnaire prior to and after shaking hands with a handshake coder. This process was repeated three times, and each participant shook hands with each of the four coders prior to the completion of the experiment. Chaplin et al. (2000) found that the individuals with firmer handshakes were more extroverted and open to experience, and these findings are shown in Table 1. These firm handshakes were predominantly males'; however, among females, those with a firmer handshake were more open to experience. Women that were more liberal, intellectual, and open to new experiences tended make a more favorable impression, and men that were less open made a more favorable impression (Chaplin et al., 2000). These findings indicate that men prefer women that are intelligent and open-minded, while women prefer men that are firm and less open to experience.

\section{Unconscious Factors of Attraction}

Physical appearance, in addition to sensory cues such as the sound of a voice and the sensation of touch, is a factor of attraction that many are consciously aware of. However, there are many factors that people are not consciously aware of, such as assessing vocabulary and a human leukocyte antigen code. Although people are not aware of these factors, they remain highly influential in attractiveness ratings.

When evaluating potential mates, women unconsciously look for signs of trustworthiness (Brooks, 8), one of the highest rated characteristics desired in a relationship (Cottrell , Neuberg, \& Li, 2007), as shown in Table 2. As Brooks describes in his novel The Social Animal (8), it is not necessary for women to consciously assess a man's trustworthiness. Instead, a woman makes a quick first impression that is surprisingly accurate in regards to how she will feel about the man months later (Willis \& Todorov, 2007). Willis and Todorov (2007) also established that men and women alike become more confident in their first impressions rather than changing them. This suggests that first impressions are crucial to a how a person's attractiveness is rated by others and is unlikely to be revised in the future. An error bias is present in both genders in regards to forming first impressions; women tend to engage in the "men are pigs" bias (Brooks, 10), unconsciously assuming that men are mainly interested in sex, while men tend to feed into this by partaking in their own error bias - the tendency to believe that there is sexual interest when there is not (Brooks, 10).

The unconscious tendency to evaluate others' intelligence via use of vocabulary is also strong in males and females (Brooks, 11). Use of words such as "designate," "ponder," or "reluctant" are indicative of an intelligence quotient over one hundred (Brooks, 2011), and intelligence and mate appeal have a positive relationship (Prokosch, Coss, Scheib, \& Blozis, 2009). Li, Bailey, Kenrick, and Linsenmeier (2002) found that both men and women find intelligence a necessity due to its various abilities that allow one to navigate the social world and raise children. Women's ability to accurately assess men's behavioral cues of intelligence at above-chance levels (Prokosch, Coss, Scheib, \& Blozis, 2009), facilitates the tendency to marry another person with whom they are intellectually compatible (Miller, 102). Thus, unconsciously evaluating another's intelligence presents benefits for both parties.

Assessing earnings-to-looks ratios, another subliminal process used to gauge attractiveness of a potential mate, is used to ensure that one gets the "greatest possible return" (Brooks, 14). A man's prosperity is proportionate to a woman's age and beauty, and a woman's attractiveness accurately predicts her husband's annual income (Brooks, 14). Women use income and social status as an indicator of a potential mate's ability to properly provide and care for their offspring (Gueguen \& Lamy, 2012), and the amount of attention a woman offers a man is positively correlated to a man's social status (DeWall \& Maner, 2008). Shackelford, Schmitt, and Buss (2005) found that the emphasis women place on financial resources and social status is significantly higher than that of men, and is exhibited around the world. Gueguen and Lamy (2012) propose that this difference can be contributed to women's ability to have comparatively less children than men, causing women to be selective in order to ensure that their children will be provided with the necessary material resources.

In addition to material resources, women are unconsciously seeking genetic resources, displayed by an increased attraction to men with a human leukocyte antigen (HLA) complex dissimilar to their own (Wedekind, Seebeck, Bettens, \& Paepke, 1995). By having women judge odors from men's t-shirts, Wedekind, Seebeck, Bettens, and Paepka (1995) were able to determine that women use sense of smell to discover men with dissimilar HLA's than themselves, as demonstrated in Figure 2. HLA is commonly referred to as major histocompatibility complex (MHC) in non-human species, and it is vital to a properly functioning immune system (Winking, Powell, Tokunaga, Takahashi, \& Juji). By detecting pathogens, HLA plays a central role in immune system responses, and choosing a mate with a dissimilar HLA than one's self (Wedekind, Seebeck, Bettens, \& Paepke, 1995) provides offspring with new alleles to protect against quickly evolving pathogens (Winking, Powell, Tokunaga, Takahashi, \& Juji). Evolving genetic components are crucial to the evolutionary process and provide an increased likelihood of offspring survival.

\section{Non-physical Factors of Attraction}

Although people may not be fully aware of the unconscious processes, such as weighing earnings-to-looks 
ratios, that contribute to how they rate others' attractiveness, many acknowledge their desire for a physically attractive mate. Many also recognize their use of non-physical factors in assessing attractiveness (e.g., similar attitudes or personality of another). The effect of these factors on the perception of physical attractiveness is statistically significant (Kniffin \& Wilson, 2004), and exists both independently and in interactions with physical factors (Swami, Greven, \& Furnham, 2007).

Common sense, in combination with recent research (Byrne \& Nelson, 1965; Lazarsfeld \& Merton, 1954; Condon \& Crano, 1988; Byrne \& Clore, 1970; Singh, Ng, Ong, \& Ling, 2008), supports the perception that similar attitudes and beliefs play a significant role in attraction. Byrne and Nelson (1965) demonstrated a positive relationship between similar attitudes and attraction through ratings of attraction based on an attitude scale provided to participants. Participants rated the stranger's intelligence, knowledge of current events, morality, adjustment, probable liking for the stranger, and probable enjoyment of working with him on 7-point scales. The results confirmed the hypothesis; attraction toward a stranger is positively related to the similar attitudes between the two people (Byrne \& Nelson, 1965).

Agreeing with another person provides one with validation for his or her own beliefs, and satisfies the drive to be logical, termed the effectance motive (Byrne \& Clore, 1970), resulting in attraction. The tendency to be attracted to others with similar attitudes and beliefs was termed "homophily" by Lazarsfeld and Merton (1954), and was further demonstrated by Singh, Ng, Ong, and Lin (2008). Children completed attitude surveys and were given experimental booklets afterwards. These booklets had an attitude survey that was alleged to have been completed by another student, and three pairs of scales to assess interpersonal attraction. Results indicated that people are attracted to those with similar attitudes as well as those they expect to be attracted to them (Singh, Ng, Ong, \& Lin, 2008). Condon and Crano (1988) further suggest that similar attitudes can indicate the probability of a mutually gratifying relationship.

Although females are more influenced by non-physical factors than males (Kniffin \& Wilson, 2004), a man's own personality can influence his preference in female body size (Swami et al., 2010). Using the International Personality Item Pool (Buchanan, Johnson, \& Goldberg, 2005), Swami, Buchanan, Furnham, and Tovee (2008) discovered that men whom are open to experience and agreeable prefer a heavier female body size, while men whom are extroverted prefer a thin female body size and find a narrower range of body sizes attractive (Swami et al., 2010). These findings are indicative of the significant effect personality characteristics have on the range and type of body sizes that men perceive to be physically attractive.

An expressive personality is often favored in all types of relationships; people who gesture and talk a lot are perceived to be socially skilled (Bernieri, Davis, Gillis, \& Grahe, 1996), and people that frequently smile are considered warm and friendly. This expressivity is among the most salient features in the behavioral stream, and plays a major role in social judgments (Bernieri, Davis, Gillis, \& Grahe, 1996). Friedman, Prince, Riggio, and DiMatteo (1980) found that expressivity is considered synonymous with charisma, and there is a tendency to be attracted to others that have an expressive personality (Buck, 1984). These findings indicate a preference for a mate that frequently smiles and has an expressive personality, and are shown in Table 3.

Arrogance is one personality trait that many express a strong contempt for, as it is typically perceived as a person attempting to say he or she is better than others and/or has a quality that others lack (Hareli \& Weiner, 2000), and Table 4 shows the positive association between this common perception and arrogancy. Schlenker and Leary (1982) revealed that people receive higher social ratings from others when they are modest versus arrogant, and that these ratings are associated with modesty not only as the achievement increases, but also as the person is more modest rather than arrogant (Hareli \& Weiner, 2000). These findings clearly demonstrate a preference for modesty in place of arrogance.

\section{Discussion}

The quick, and often long-lasting, first impressions formed when assessing another's attractiveness encompass various factors ranging from physical to non-physical. Although men are assumed to place a sole emphasis on physical appearance, it is also valued by women (Caryl et al., 2009). Physical factors are not limited to body shape and facial features; displays of color on the body and handshake characteristics are also physical influences on attractiveness ratings. Men and women also unconsciously partake in error biases and intelligence evaluations, attempting to achieve the greatest possible return (Brooks, 14). However, the most influential factor on attractiveness ratings is personality; open-mindedness, an expressive personality, and even modesty can contribute to one's attractiveness as perceived by others. Interpersonal attraction is based on various assessments, physical, unconscious, and non-physical, that people make of others and these assessments are influenced by multiple factors.

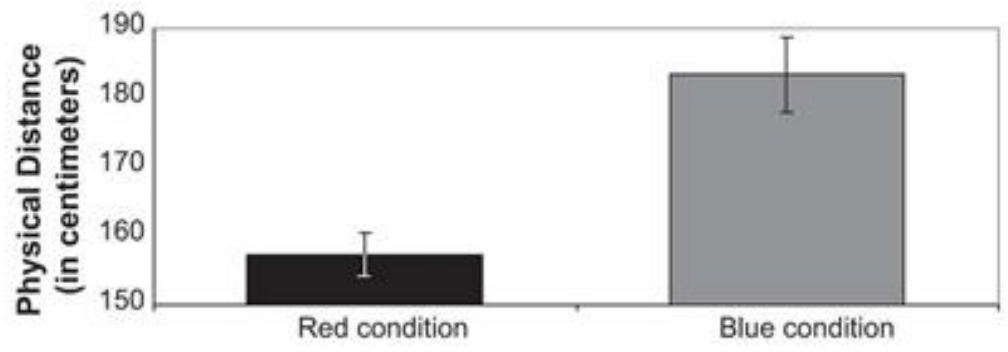

Figure 1. Physical distance in centimeters as a function of color condition 
Table 1. Correlations Between a Firm Handshake and Personality Scales

\begin{tabular}{lc}
\hline \multicolumn{1}{c}{ Personality scale } & $\begin{array}{c}\text { Firm Handshake } \\
\text { Composite }\end{array}$ \\
\hline Shyness & -.29 \\
Neuroticism & -.24 \\
Openness & .20 \\
Extraversion & .19 \\
Emotional Expression & .16 \\
Positive Affect & .14 \\
Negative Affect & -.09 \\
Conscientiousness & -.08 \\
Agreeableness & -.06 \\
\hline
\end{tabular}

Note: $\mathrm{N}=112$. Correlations larger than .19 are significant at $\mathrm{p}$

$$
<.05 \text {. }
$$

Table 2. Importance of Traits for the Ideal Person

\begin{tabular}{lccc}
\hline & & \multicolumn{2}{c}{$\begin{array}{c}\text { Most necessary } \\
\text { nominations (\%) }\end{array}$} \\
\cline { 3 - 4 } & $\begin{array}{c}\text { Mean } \\
\text { importance } \\
\text { Tikait category }\end{array}$ & $\begin{array}{c}\text { Chance } \\
\text { level }\end{array}$ & $\begin{array}{c}\text { Observed } \\
\text { frequency }\end{array}$ \\
\hline Trustworthiness & $\mathbf{8 . 1 5}$ & 16.1 & $\mathbf{6 5 . 9}$ \\
Cooperativeness & $\mathbf{7 . 2 6}$ & 16.1 & 4.5 \\
Agrecableness & $\mathbf{7 . 2 6}$ & 9.7 & 4.5 \\
Extraversion & $\mathbf{7 . 0 5}$ & 12.9 & 2.3 \\
Conscientiousness & 5.95 & 6.5 & 2.3 \\
Emotional stability & $\mathbf{7 . 0 5}$ & 9.7 & 13.6 \\
Open-mindedness & 6.84 & 6.5 & 2.3 \\
Intelligence & $\mathbf{7 . 0 0}$ & 6.5 & 4.5 \\
Assertiveness & 5.67 & 3.2 & 0 \\
Attractiveness & 6.50 & 3.2 & 0 \\
Physical health & $\mathbf{7 . 4 8}$ & 3.2 & 0 \\
Similarity & 5.19 & 3.2 & 0 \\
Predictability & 3.90 & 3.2 & 0 \\
\hline
\end{tabular}

Note: Mean Likert-scale importance ratings in boldface found to be significantly more important than others traits, and asterisks indicate traits predicted to be particularly important. Observed most necessary frequencies in boldface are significantly greater than the chance level frequency at $\mathrm{p}<$ .05 .

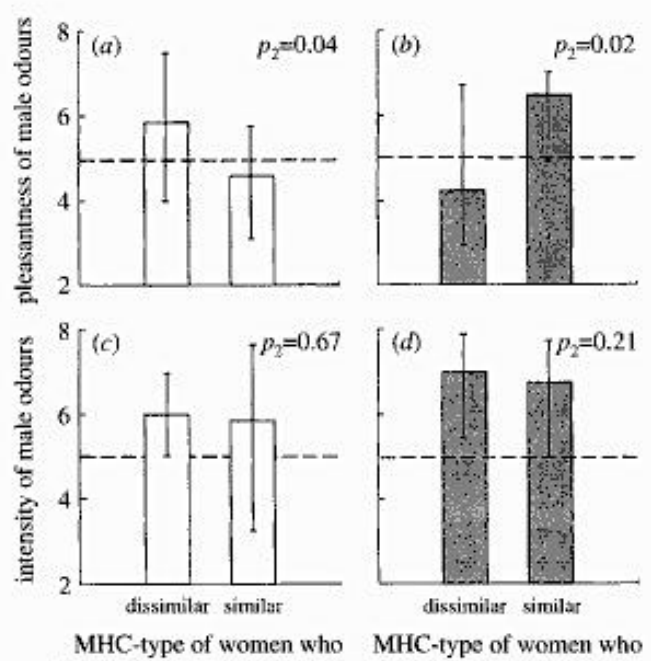

do not take oral contraceptives take oral contraceptives

Figure 2. Average score per male by females who are dissimilar or similar on their MHC. The odors were judged by both females who did and did not take oral contraceptives.

Table 3. Cue Correlations with Consensual Judgment

\begin{tabular}{lcc}
\hline \multicolumn{1}{c}{ Cue } & $\begin{array}{c}\text { Mean cue } \\
\text { depende icy } \\
\left(z_{r}\right)\end{array}$ & $\begin{array}{c}\text { Correlation with } \\
\text { conscrisual judgment } \\
(r)\end{array}$ \\
\hline Adaptors & .04 & .05 \\
Mean attractiveness & .18 & .23 \\
Attractiveness discrepancy & -.02 & -.02 \\
Back+channel responses & $.37^{* *}$ & $.48^{* * * *}$ \\
Expressivity & $.48^{* * *}$ & $.61^{* * *}$ \\
Eyc contact & .15 & .22 \\
Forward lean & .08 & .10 \\
Gestures (female) & .11 & .16 \\
Gestures (male) & .12 & .16 \\
Mutual silence & -.10 & -.14 \\
Nervous behavior & -.22 & $-.31^{*}$ \\
Orientation & -.03 & -.04 \\
Postute shifts & .14 & .20 \\
Proximity & $.37^{* *}$ & $.48^{* * *}$ \\
Racial similarity & -.21 & $-.28^{*}$ \\
Smiling & $.39^{* *}$ & $.51^{* * *}$ \\
Synchrony & .26 & $.35^{*}$ \\
\hline
\end{tabular}

$* 0<.05 . \quad * * p<.03 . \quad * * * p<.001$.

Table 4. Correlations Among Modesty, Arrogance,

Desirability of the Cause, the Degree to Which the Person

Thinks He is Better than Others, and That He Has a Quality

That Others Lack

\begin{tabular}{lccccc}
\hline \multicolumn{1}{c}{ Variable } & 1 & 2 & 3 & 4 & 5 \\
\hline 1. Arrogance & & & & & \\
2. Modesty & $-.56^{* *}$ & & & & \\
3. Thinks he is better & $.63^{* *}$ & $-.37 * *$ & & & \\
4. Thinks he has a quality that others lack & $.50^{* *}$ & $-.31^{* *}$ & $.66^{* *}$ & & \\
5. Desirable cause & $.22^{* *}$ & $-.23^{* *}$ & $.41^{* *}$ & $.42^{* *}$ & \\
$M$ & 3.22 & 4.58 & 3.41 & 3.51 & 4.13 \\
$S D$ & 1.82 & 1.56 & 1.66 & 1.76 & 1.93 \\
\hline
\end{tabular}


Note: $\mathrm{N}=101$. Ratings were made on 7-point Likert scales. Higher values indicate a greater degree of that variable. $* \mathrm{p}<.05 . * * \mathrm{p}<.01$

\section{References}

Bernieri, F. J., Davis, J. M., Gillis, J. S., \& Grahe, J. E. (1996). Dyad rapport and the accuracy of its judgment across situations: A lens model analysis. Journal of Personality and Social Psychology, 71 (1), 110-129.

Bielert, C., Girolami, L., \& Jowell, S. (1989). An experimental examination of the color component in visually mediated sexual arousal of the male chacma baboon. Journal of the Zoological Society of London (219), 569-579.

Brooks, D. (2011). The Social Animal: The Hidden Sources of Love, Character, and Achievement. New York: Random House.

Buchanan, T., Johnson, J. A., \& Goldberg, L. R. (2005). Implementing a five-factor personality inventory for use on the Internet. European Journal of Psychological Assessment, 21, 115-127.

Buck, R. (1984). The communication of emotion. New York: Guilford Press.

Buss, D. M. (2003). The Evolution of Desire: Strategies of Human Mating. New York: Basic Books.

Byrne, D., \& Clore, G. (1970). A reinforcement model of evaluative responses. 1, 103-128.

Byrne, D., \& Nelson, D. (1965). Attraction as a linear function of proportion of positive reinforcements. Journal of Personality and Social Psychology, 1 (6), 659-663.

Caryl, P. G., Bean, J. E., Smallwood, E. B., Barron, J. C., Tully, L., \& Allerhand, M. (2009). Women's preference for male pupil-size: Effects of conception risk, sociosexuality and relationship status". Personality and Individual Differences , 46 (4), 503-508.

Chaplin, W. F., Phillips, J. B., Brown, J. D., Clanton, N. R., \& Stein, J. L. (2000). Handshaking, Gender, Personality, and First Impressions. Journal of Personality and Social Psychology, 79 (1), 110-117.

Condon, J. W., \& Crano, W. D. (1988). Inferred evaluation and the relation between attitude similarity and interpersonal attraction. Journal of Personality and Social Psychology , 54 (5), 789-797.

Cottrell , C. A., Neuberg, S. L., \& Li, N. P. (2007). hat do people desire in others? A sociofunctional perspective on the importance of diferent valude characteristics. Journal Personality and Social Psychology, 92 (2), 208-231.

DeWall, C. N., \& Maner, J. K. (2008). High status men (but not women) capture the eye of the beholder. Evolutionary Psychology, 6 (2), 328-341.

Friedman, H. S., Prince, L. M., Riggio, R. E., \& DiMatteo, M. R. (1980). Understanding and assessing nonverbal expressiveness: The affective communication test. Journal of Personality and Social Psychology, 39, 333-351.

Furnham, A., Moutafi, J., \& Baguma, P. (2002). A crosscultural study on the role of weight and waist-to-hip ratio on female attractiveness. Personality and Individual Differences , 32 (4), 729-745.

Grundl, M., Knoll, S., Eisenmann-Klein, M., \& Prantl, L. (2012). The blue-eyes stereotype: Do eye color, pupil diameter, and scleral color affect attractiveness? Aesthetic Plastic Surgery, 36 (2), 234-240.

Gueguen, N., \& Lamy, L. (2012). Men's social status and attractiveness: Women's receptivity to men's date requests. Swiss Journal of Psychology, 71 (3), 157-160.

Hareli , S., \& Weiner, B. (2000). Accounts for success as determinants of perceived arrogance and modesty. Motivation and Emotion, 24 (3), 215-236.

Kayser, D. N., Elliot, A. J., \& Feltman, R. (2010). Red and romantic behavior in men viewing women. European Journal of Social Psychology (40), 901-908.

Kniffin, K. M., \& Wilson, D. S. (2004). The effect of nonphysical traits on the perception of physical attractiveness: Three naturalistic studies. Evolution and Human Behavior (25), 88-101.

Li, N. P., Bailey, J. M., Kenrick, D. T., \& Linsenmeier, J. A. (2002). The nececessities and luxuries of mate preferences: Testing the tradeoffs. Journal of Personality and Social Psychology, 82 (6), 947-955.

Merriam-Webster. (n.d.). Attraction.

Miller, G. (2006). The mating mind: How sexual choice shaped human nature. New York: Touchstone.

Prokosch, M. D., Coss, R. G., Scheib, J. E., \& Blozis, S. A. (2009). Intelligence and mate choice: Intelligent men are always appealing. Evolution and Human Behavior, 30, 1129.

Sammaknejad, N. (2013). Facial attractiveness: The role of iris size, pupil size, and scleral color. Dissertation Abstracts International: Section B: The Sciences and Engineering , 74 (5-B).

Schlenker, B. R., \& Leary, M. R. (1982). Audience's reactions to self-enhancing, self-denigrating, and accurate selfpresentations. Journal of Experimental Social Psychology, $18,89-104$.

Shackelford, T. K., Schmitt, D. P., \& Buss, D. M. (2005). Universal dimensions of human mate preferences. Personality and Individual Differences , 39, 447-458.

Singh, R., Ng, R., Ong, E. L., \& Lin, P. K. (2008). Different mediators for the age, sex, and attitude similarity effects in interpersonal attraction. Psychology Press (30), 1-17.

Swami, V., Buchanan, T., Furnham, A., \& Tovee, M. J. (2008). Five-factor personality correlates of perceptions of women's body sizes. Personality and Individual DIfferences , 45, 697-699.

Swami, V., Furnham, A., Chamorro-Premuzic, T., Akbar, K., Gordon, N., Harris, T., et al. (2010). More than just skin deep? Personality information influences men's ratings of the attractiveness of women's body sizes. The Journal of Social Psychology, 150 (6), 628-647.

Swami, V., Greven, C., \& Furnham, A. (2007). More than just skin-deep? A pilot study integrating physical and nonphysical factors in the perception of physical attractiveness. Personality and Individual Differences (43), 563-572.

Waitt, C., Gerald, M. S., Little, A. C., \& Krasielburd, E. (2006). Selective attention toward female secondary sexual characteristics. American Journal of Primatology (68), 738744.

Wedekind, C., Seebeck, T., Bettens, F., \& Paepke, A. J. (1995). MHC-dependent mate preferences in humans. Proceedings: Biological Sciences, 260 (1359), 245-249.

Willis, J., \& Todorov, A. (2007). Predicting Political Elections from Rapid and Unreflective Face Judgment. 
Proceedings of the National Academy of Sciences of the United States of America, 104 (46), 17948-53.

Winking, J., Powell, J., Tokunaga, K., Takahashi, K., \& Juji,

T. (n.d.). A population-level test of human negative assortative mating along HLA class I and class II loci. Retrieved July 9, 2014, from The University of New Mexico: http://www.unm.edu/ jwinking/HLA.pdf 